S. Borel ; and at Oxford that great teacher Professor $T$. Pomfret Kilner (1890-1964) was also perfecting techniques for their closure.

Free-skin grafting became practicable after descriptions by a Swiss working in Paris, Jacques L. Reverdin, in 1869, of pinch grafts ; by Louis Ollier, of Lyon, in 1872, and the German, Carl Thiersch, in 1874, of partial-thickness grafts ; and by John R. Wolfe, a Hungarian working in Glasgow, of full-thickness grafts, which he reported in the B.M.f. ${ }^{1}$ The Dutch surgeon Johannes F. Esser in 1917 described skin grafting inside the mouth, and Gillies was quick to seize upon and improve the technique of the epithelial inlay.

Much of Gillies's early work with facial-flap repairs was coloured by his study of original papers from Germany by Johann M. von Langenbeck (1776-1850), Carl F. von Graefe (1787-1840), and Friedrich Dieffenbach (1795-1847). However facial flaps have been in use for some three millennia, their origin dating from the rhinoplasty described by Sushruta Samhita, of India, in about 800 B.C. This operation was introduced into Europe via London in 1814 by Joseph C. Carpue and into America via New York in 1835 by Jonathon $M$. Warren. The first operation to move tissue from one part of the body to a distal part came from Sicily, and was described by Gaspare Tagliacozzi, of Bologna, in 1597. His account of the use of a forearm flap to reconstruct a nose is so precise that his practical instructions are still useful. He was also the first to illustrate a surgical textbook with plentiful accurate diagrams. Much later John Balazza (1814-1868), a Hungarian, was the first to use clinical photographs to illustrate facial reconstructive surgery. The origin of the technique which employs adjacent triangular transposed flaps to lengthen a linear contracture, the Z-plasty, is unknown, but it was described by C. P. Denonvilliers in 1856. Before effective surgical operations were devised facial prostheses were accepted, and they remained in common use up to and during the first years of the 1914-18 war, until Sir Harold Gillies made them superfluous.

\section{Mucolytic Agent}

An increase in the viscosity of the mucus secreted by the bronchial glands hinders transport of it by ciliary action along the bronchi and is likely to cause respiratory obstruction. Mucus becomes more viscous when the patient is dehydrated or when the mucus itself is exposed to dry air or oxygen. Some drugs increase its viscosity-for example, the antihistamines, ${ }^{1}$ and so does admixture with pus, blood, or fibrin. But the most intractable type of sticky mucus is found in fibrocystic disease of the pancreas (mucoviscidosis), in which the composition of the mucus throughout the body is abnormal. Severe and progressive pulmonary damage is almost invariable in this condition from blocking of the bronchi and bronchioles with sticky infected mucus.

Many attempts have been made to reduce the viscosity of mucus. Until recently water was the most effective agent. In cases of laryngo-tracheobronchitis and after tracheostomy the viscosity can be reduced by preventing dehydration and giving aerosols. A similar approach helps the patient in status asthmaticus, when persistent respiratory obstruction may be due not to bronchial spasm but to the plugging of the bronchi by mucus. ${ }^{2}$ This state of affairs may be made worse by overdosage with aminophylline and related compounds ${ }^{3}$ or by the inappropriate use of antihistamine drugs in an acute attack. Patients with fibrocystic disease derive benefit from aerosol therapy with $10 \%$ propylene glycol in water. ${ }^{45}$

The use of chemical agents to liquefy mucus or mucopus has in the past been largely unsuccessful. Various enzymes, such as streptodornase, streptokinase, and trypsin have been tried, as have a number of surface-active agents (detergents). However, a newly introduced compound, $\mathrm{N}$-acetylcysteine (N.A.C.), shows considerable promise. Its action depends on the possession of a free sulphydryl group which opens up the disulphide bonds of the molecule of mucus, causing a reduction in viscosity. It also appears to have a liquefying action on the deoxyribonucleic acid which is responsible for the viscosity of pus, but it is inactive against fibrin or blood clot. N.A.C. is active at physiological $p \mathrm{H}$ and up to a maximum of $p \mathrm{H} 8.0$; its greatest effect occurs within five to ten minutes. It can be used as a $10-20 \%$ solution in the form of an aerosol given continuously or intermittently or it can be instilled directly through a tracheostomy or intratracheal catheter. ${ }^{6}$ W. R. Webb ${ }^{6}$ has reported satisfactory results in chronic bronchitis and post-operative cases, and A. Reggiani and his colleagues $^{7}$ also observed improvement in chronic bronchitis when N.A.C. was combined with a tetracycline compound. I. A. Meeker and W. N. Kincannon ${ }^{8}$ used N.A.C. to liquefy the intestinal contents in meconium ileus of the newborn.

Experience is still insufficient to judge the results of its use in the management of fibrocystic disease. A. L. Sheffner and his co-workers ${ }^{9}$ showed that it did reduce the viscosity of the tracheobronchial secretions in a number of conditions and found it was active in the presence of pus ; only one of their specimens was obtained from a patient with fibrocystic disease and this showed a marked reduction in viscosity. Similar results were obtained by H. W. Reas ${ }^{10}$ in the sputum from two patients with fibrocystic disease. He also studied the clinical responses and changes in respiratory function in 28 patients with this condition over periods from 10 weeks to 38 months: ${ }^{11}$ In mild cases N.A.C. showed no improvement over conventional methods of treatment (including aerosols), but the moderately affected patients did benefit, while the severe cases showed a transient improvement. In long-standing atelectasis in fibrocystic disease S. R. Schuster and colleagues ${ }^{12}$ were unable to obtain re-expansion after bronchial lavage with N.A.C. Webb ${ }^{13}$ treated 13 cases of fibrocystic disease by nebulization with N.A.C. for periods up to two years, with improvement.

Some possible disadvantages of N.A.C. should be mentioned. Both as a liquid solution and as an aerosol N.A.C. reacts with rubber, iron, and copper, so that apparatus for use with it requires careful choice. There is also a danger, particularly in the severely ill patient, of pooling of the liquefied secretions in the terminal bronchi. Caution should be

\footnotetext{
Ratner, B., Pediatrics, 1959, 23, 781.

Richards, W., and Patrick, J. R., Amer. F. Dis. Child., 1965, 110, 4

Soifer, H., f. Pediat., 1957, 50, 657.

Matthews, L. W., ei al., ibid., 1964, 65, 558.

5 Doershuk, C. F., et al., ibid., 1964, 65, 677

6 Webb, W. R., f., thorac. cardiovasc. Surg., 1962, 44, 330. Reggiani, A., Gulzigna, L., and Gaffuri, E., Minerva med., 1963, 54,
3608.

- Meeker, I. A., and Kincannon, W. N., Surgery, 1964, 56, 419. Sheffner, A. L., Medler, E. M., Jacobs, L. W., and Sarett, H. P., Amer.
Rev. resp. Dis., 1964, 90, 721.

10 Reas, H. W., F. Pediat., 1963, 62, 31.

11 ibid., 1964, 65, 542 .

Schuster, S. R., Schwachman, H., Harris, G. B. C., and Kon-Taik Wew, thorac. cardiovasc. Surg., 1964, 48, 750

4 ebb, W. R., Postgrad. Med., 1964, 36, 449

15 Lernstein, I. L., and Ausdenmoore, R. W., Dis. Chest, 1964, 46, 469.

15 Lawson, D., and Saggers, B. A., Brit. med. F., 1965, 1, 317 .

American Medical Association Council on Drugs, $\mathcal{F}$. Amer. med. Ass.,
1964, 147.
} 
used when giving N.A.C. to asthmatics, as I. L. Bernstein and R. W. Ausdenmoore ${ }^{14}$ have reported bronchial spasm in 8 out of 11 such patients in whom it was tried out. Lastly, little is yet known about the effect of N.A.C. on other agents used in the treatment of chronic chest disease. For instance, D. Lawson and B. A. Saggers ${ }^{15}$ have reported that N.A.C. is destroyed by high concentrations of oxygen, and that N.A.C. itself may inactivate many of the penicillins, tetracycline, and cephaloridine.

In short, $\mathrm{N}$-acetylcysteine may have a place in the management of chronic bronchitis, tracheostomy, and certain postoperative cases. Its effectiveness in the long-term therapy of fibrocystic disease awaits a carefully controlled study. ${ }^{16}$

\section{Evening Colic}

Not all babies who cry have colic. They cry because they are hungry, wet, cold, hot, or bored among other reasons. They cry when they have "wind" in the stomach. The usual cause of this in a breast-fed baby is sucking too long or sucking on an empty breast, and in a bottle-fed baby the usual cause is too small a hole in the teat. In these circumstances the feed takes too long, the baby swallows air, and so has " wind," for all wind in the stomach of babies is air which has been swallowed.

"Colic" is a nonspecific term which some writers loosely apply to babies who cry for any of the reasons mentioned above. True evening colic, however, termed by some " three months colic," is a different matter altogether. This is almost confined to the evenings, beginning a few days after birth, in hospital or at home, and clearing up within three or four months. There are all grades of severity from mild fussiness in the evenings to severe rhythmical attacks of screaming obviously intestinal in origin, each attack lasting a few minutes, followed by a few minutes' quiet. The attacks are often accompanied by loud borborygmi, and are relieved by the passage of flatus per rectum. The subject has been well reviewed by $\mathrm{R}$. S. Illingworth. ${ }^{12}$

Many theories of the cause of evening colic have been propounded. They include allergy, hypertonia, underfeeding, overfeeding, or the feeds being too hot, too cold, too frequent, too infrequent, too weak, too strong, or containing too much fat, carbohydrate, or protein. Some physicians have suggested that the colic is due to disease of the alimentary tract, urinary system, gall-bladder, bones, nose, or ears. Others have said that it is due to syphilis, fatigue toxins in the mother, or to the abdominal binder. ${ }^{1}$ One writer suggested that it is due to "bouncing the baby" too much; another that it is due to the father smoking when he comes home; yet another that when the father comes home he upsets his wife, so that by some means unspecified the baby develops colic. In fact it is perfectly easy to eliminate all these theories. The incidence of evening colic bears no relationship to the type, temperature, or quantity of feed. And it is not associated with organic disease, because it occurs in well, thriving babies who remain well, and who are happy except in the evenings. Neither is there any connexion with "hypertonia."

It has been suggested recently that colic is related to progesterone deficiency. ${ }^{3}$ Fifteen non-colicky infants excreted in the urine appreciable amounts of pregnanediol glucuronide, while fifteen colicky babies did not, and there seemed to be clinical improvement on hormone treatment. Psychiatrists have repeatedly declared that the colic is due to maternal anxiety, though none of them have explained how this causes rhythmical attacks of intestinal colic. M. Lakin, ${ }^{4}$ for instance, declared that mothers of colicky babies have poorer parentchild relationships, greater concern over their adequacy as women, less adequate marital adjustment, and less mothering love than the mothers of control children. Others have written that colic is " the earliest response to the presence of tension in the environment." 5 J. W. Bruce ${ }^{6}$ appears to suggest that the babies are malingering, for he wrote, "I feel sure of one thing-the infants are usually not in as much pain as they appear to be, or as their parents think they are." Now J. L. Paradise, ${ }^{7}$ working at the Rochester Child Health Centre, has carried out a valuable study of the mothers of colicky babies. He showed that the incidence of colic was unrelated to social class, the mother's age, the birth order, the child's sex, the weight gain, the type of feeding, or a history of allergic disease-as Illingworth had shown. ${ }^{1}$ But Paradise studied the emotional make-up of the mothers and carried out psychological tests. He concluded that there is no relation to maternal emotional factors, but that there is some association with superior maternal intelligence-perhaps because of better maternal reporting or lower maternal tolerance. He found that most of the mothers were "stable, cheerful, and feminine."

The fact is that we do not know the cause of evening colic. It seems likely that it is somehow related to immaturity, but we do not know how. It seems to be related to wind becoming blocked in loops of bowel, but the reason for this is unknown. It is not due to gastric flatulence. ${ }^{1}$ Paradise described some peculiar observations on the effect of sound and vibrations on the colic. He wrote, "It is curious that otherwise inconsolable infants were quieted by exposure to various sounds or vibrations-sounds of motors, vacuum cleaners or washing machines." He thought that the colic might be an expression of immaturity of the central nervous system, perhaps genetically determined, and that the improvement in response to sucking, vibrations or sounds, rocking or enemas, may be due to interruption or decrease in certain afferent proprioceptive stimuli.

It is essential to be sure that the diagnosis is correct and that the crying is not merely due to hunger or the desire to be picked up. It is easy to make sure that the colic is not due to hunger. This is important in babies who are fully breast-fed, for the supply of milk is apt to fall off in the late afternoon and evening. It is easy to determine whether he is merely crying to be picked up and cuddled, for the baby with colic continues to scream in his mother's arms. Whatever the cause, it has been shown that the anticholinergic drug dicyclomine hydrochloride, ${ }^{8}$ a teaspoonful of the syrup before the evening feed, will relieve the symptoms if the diagnosis is correct.

1 Illingworth, R. S., Arch. Dis. Childh., 1954, 29, 165.

2 The Normal Child, 1964, 3rd ed. Churchill, London.

s Clark, R. L., Ganis, F. M., and Bradford, W. L., Pediatrics, 1963, 31, 65.

- Lakin, M., Monograph of the Society for Research in Child Development, 1957, 22, 7. 5 Wessel, M. A., Cobb, J. C., Jackson, E. B., Harris, G. S., and Detwiler,

- Bruce, J. W., Pediat. Clin. N. Amer., 1961, 8, 143.

7 Paradise, J. L., f. Amer. med. Ass., 1966, 197, 191.

- Illingworth, R. S., Lancet, 1959, 2, 1119. 